\title{
Effect of Solidification and Cooling Methods on the Efficacy of Slag as a Feedstock for $\mathrm{CO}_{2}$ Mineralization
}

\author{
Corey Adam MYERS ${ }^{1) *}$ and Takao NAKAGAKI ${ }^{21}$ \\ 1) Graduate School of Creative Science and Engineering, Waseda University, Okubo, Shinjuku-ku, Tokyo, 169-8555 Japan. \\ 2) Faculty of Modern Mechanical Engineering, Waseda University, Okubo, Shinjuku-ku, Tokyo, 169-8555 Japan.
}

(Received on August 10, 2017; accepted on October 4, 2017)

\begin{abstract}
Iron and steel making (ISM) slag is often utilized to partially offset $\mathrm{CO}_{2}$ emissions associated with metal production. Currently, the primary recycling method for slag is as $\beta-\mathrm{Ca}_{2} \mathrm{SiO}_{4}$ utilized in the cement industry, termed ground granulated blast furnace slag (ggbs). However, the cement market is not large enough to exploit the entirety of ISM slag as ggbs, relegating a large quantity of slag to reuse pathways with minor impacts on $\mathrm{CO}_{2}$ reduction. Recent years have seen an increase in research into mineralizing $\mathrm{CO}_{2}$ using the $\mathrm{Ca}$ and $\mathrm{Mg}$ content of ISM slags as a feedstock. Unfortunately, it has not been widely recognized that the solidification and cooling processes of slag dramatically effects its efficacy as a $\mathrm{CO}_{2}$ mineralizing feedstock via modification of mineralogy, crystallinity, grain size, and micromorphology. This paper clarifies the key properties determining mineralization effectiveness and elucidates how to control these properties during the solidification and cooling process. The effect of solidification and cooling method on net $\mathrm{CO}_{2}$ reduction is shown to be strongly dependent on solidification and cooling method along with the $\mathrm{CO}_{2}$ intensity of energy generation.
\end{abstract}

KEY WORDS: slag; ironmaking; steelmaking; mineralization; CCUS; ggbs; $\mathrm{CO}_{2}$.

\section{Introduction}

The iron and steel making (ISM) industry contributes significantly to rising global greenhouse gas concentrations with the slag waste stream of ISM embodying a large quantity of $\mathrm{CO}_{2}$ related to the calcination of $(\mathrm{Ca}, \mathrm{Mg}) \mathrm{CO}_{3}$ and the heating of slag within the furnace. Efforts to offset the $\mathrm{CO}_{2}$ associated with slag have occurred primarily via recycling slag to cement production (ggbs) $)^{1)}$ and more recently by integrating said process with the recovery of heat from slag. ${ }^{2)}$ Neglecting the energy to solidify, grind, dry, and transport ggbs, the use of slag in cement production reduces $\mathrm{CO}_{2}$ emissions by $\sim 0.580 \mathrm{gCO}_{2} / \mathrm{kg}$-ggbs. ${ }^{3)}$ In comparison, 1 kilogram of $\mathrm{Ca}_{2} \mathrm{SiO}_{4}$ slag can potentially mineralization $\sim 0.511 \mathrm{~kg}$ of $\mathrm{CO}_{2}$ as $\mathrm{CaCO}_{3}$ (again, neglecting operational energy). The superior $\mathrm{CO}_{2}$ reduction of ggbs is due to avoiding the fossil fuel combustion associated with the heating and decomposition of $(\mathrm{Ca}, \mathrm{Mg}) \mathrm{CO}_{3}$ into $(\mathrm{Ca}, \mathrm{Mg}) \mathrm{O}$ and $\mathrm{CO}_{2}$. In terms of $\mathrm{CO}_{2}$ reduction, ggbs is the current optimal reuse pathway for slag; however, the potential market size for ggbs is on the order of $145 \mathrm{MT} / \mathrm{y}$, while the production of BF slags is on the order of 272-327 MT/y. ${ }^{4)}$ There is an additional 145-218 MT/y of steel slag from BOF and EAF operations, the majority of which do not have the proper chemistry for utilization as ggbs, regardless of market availability. Based on simple conversion of the $\mathrm{Ca}$ and $\mathrm{Mg}$ con-

\footnotetext{
* Corresponding author: E-mail: corey.a.myers@moegi.waseda.jp
} DOI: http://dx.doi.org/10.2355/isijinternational.ISIJINT-2017-478 tent, the ISM slag relegated to reuse outside of ggbs contains $\sim 103-150 \mathrm{MT} / \mathrm{y}$ of unexploited $\mathrm{CO}_{2}$ capturing potential.

In recent years, research has focused on recovering heat from slags such that meaningful $\mathrm{CO}_{2}$ reductions can be garnered from slag, regardless if it is to be recycled as ggbs or not. In particular, the advancement of air-based heat recovery methods has increased the extraction of usable heat from slags. However, the potential $\mathrm{CO}_{2}$ reduction gained via heat recovery is small when compared to the potential of slag to mineralize $\mathrm{CO}_{2}$. Under idealized conditions, ${ }^{5)}$ the recovery of heat from slag instead of production by a current natural gas oven ${ }^{6}$ would offset $\sim 0.117 \mathrm{kgCO}_{2} / \mathrm{kg}$-slag. Further, the application of air-based heat recovery to steel slags has technical and economic issues that remain to be solved. ${ }^{7)}$

$\mathrm{CO}_{2}$ mineralization using the $\mathrm{Ca}$ and $\mathrm{Mg}$ content of ISM slags has received substantial research as conversion of (Ca, $\mathrm{Mg})$-silicates to $(\mathrm{Ca}, \mathrm{Mg})$-carbonates is exothermic and slag is conveniently located adjacent to a concentrated $\mathrm{CO}_{2}$ source. The theoretical $\mathrm{CO}_{2}$ capture potential is dependent on the total $(\mathrm{Ca}, \mathrm{Mg})$ content of an ISM slag, and thus has significant variability from $\sim 0.243-0.519 \mathrm{kgCO}_{2} / \mathrm{kg}$-slag. ${ }^{8,9)}$ However, experimental difficulties related to slow reaction kinetics, the formation of passivating product layers (PL), and the trapping of mineral grains within unreactive species (mineral locking, ML) has substantially lowered the net $\mathrm{CO}_{2}$ reduction provided by slag. To enhance the reaction kinetics researchers have explored a variety of mechanical, thermal, and chemical methods. There is a tendency in the field to assume the utilization of renewable energy directly 
for process operation and to ignore the $\mathrm{CO}_{2}$ associated with chemical production; resulting in erroneously overstated net $\mathrm{CO}_{2}$ reductions. However, the most effective use of renewable energy towards $\mathrm{CO}_{2}$ reductions is as a direct replacement for $\mathrm{CO}_{2}$-intensive energy sources. ${ }^{10)}$ Moreover, extant infrastructure and current investments into fossil fuel power sources implies that utility-scale energy will maintain a non-trivial $\mathrm{CO}_{2}$ footprint at least until 2040. ${ }^{11)}$ As the intent of slag-based $\mathrm{CO}_{2}$ mineralization is to assist in reduction of global $\mathrm{CO}_{2}$ emissions, it is mandatory to account for $\mathrm{CO}_{2}$ associated with the energy and chemical consumption. When all sources of $\mathrm{CO}_{2}$ are considered, the net $\mathrm{CO}_{2}$ reduction of thermochemical slag-based $\mathrm{CO}_{2}$ mineralization methods decreases substantially. ${ }^{12)}$ In this paper, the discussion is limited to slag-based $\mathrm{CO}_{2}$ mineralization that occurs under atmospheric pressure, mild temperatures, and without chemical additives.

Despite decades of research, the majority of the literature either completely neglects or fails to adequately quantify the most fundamental characteristics of the slag that effect $\mathrm{CO}_{2}$ mineralization: namely, mineralogy, crystallinity, grain size distribution (GSD), micromorphology, and the particle size distribution (PSD). The large variability in these characteristics introduces significant noise into experimental data; consequently, logically consistent trends about the effectiveness of operating parameters such as liquid-to-solid ratio, temperature, $\mathrm{CO}_{2}$ partial pressure, and reaction time remain elusive. ${ }^{13)}$ Further, there is a failure to recognize that these traits are in large part controlled by the slag solidification and cooling processes employed at ISM facilities. This paper posits that slag-based $\mathrm{CO}_{2}$ mineralization efficacy can be improved by control of the solidification- and coolingdependent mineralogy, structure, and micromorphology of slags. In the next section, the dependence of slag-based $\mathrm{CO}_{2}$ mineralization efficacy on slag mineralogy, crystallinity, GSD, micromorphology, and PSD are quantitatively discussed. Then, in section three, the control of these properties through the solidification and cooling process is elucidated. The net impact of solidification and cooling methods on slag-based $\mathrm{CO}_{2}$ mineralization efficacy is quantified for prototypical iron slag and steel slag in section four.

\section{Mechanisms Underlying $\mathrm{CO}_{2}$ Mineralization Sus- ceptibility of ISM Slag}

\subsection{Mineralogy and Crystallinity}

In the slag-based $\mathrm{CO}_{2}$ mineralization field, detailed study of the impact of mineralogy on mineralization efficacy is sparse. Despite studies highlighting the mineralogical variation between ISM facilities, ${ }^{14)}$ the typical reported information is limited to the slag source (e.g., BF, BOF, EAF) and the elemental composition as simple oxides. Work from the silicate rock-based $\mathrm{CO}_{2}$ mineralization field has shown that the ostensibly similar $\mathrm{Mg}_{2} \mathrm{SiO}_{4}$ and $\mathrm{CaSiO}_{3}$ differ in $\mathrm{CO}_{2}$ mineralization depth by $\sim 4$ orders of magnitude $\left(\leq 40 \mathrm{~nm}^{16}\right)$ and $\geq 125 \mu \mathrm{m},{ }^{17)}$ respectively), despite comparable thermodynamic driving forces $\left(\Delta G_{r}=-34.7 \mathrm{~kJ} / \mathrm{mol}\right.$ and -39.5 $\mathrm{kJ} / \mathrm{mol}$, respectively) and dissolution rates. ${ }^{18)}$ Though thermodynamics determines the initial surface reactions, the activation energy is structurally-dependent, ${ }^{19)}$ and the mineralogy determines the PL characteristics which are the pri- mary inhibitory feedback on $\mathrm{CO}_{2}$ mineralization reactions.

To quantitatively assess the importance of mineralogy in $\mathrm{CO}_{2}$ mineralization, Bodor et al. ${ }^{20)}$ and Ashraf and Olek ${ }^{21)}$ reacted synthetic minerals common to slag using autoclave reactors. These mild conditions are consistent with processes that may result in net $\mathrm{CO}_{2}$ reduction and remove many of the complicating factors extant in more sophisticated reactor designs. Ashraf and Olek provided complete PSD graphs, allowing for accurate determination of reaction depth. Unfortunately, Bodor et al. did not adequately quantify the PSD. Because the powder generation methods were similar between the studies, the minimum and maximum PSD's from Ashraf and Olek's work were used to quantify the PL thickness in Bodor et al.'s work. The results, displayed in Table 1, indicate $\sim 2$ orders of magnitude variation in PL thickness between the minerals studied. Unfortunately, calcium aluminosilicate compounds, common to ironmaking slag, were not included in the studies.

\subsection{Surface Area}

Increasing the specific surface area (i.e., the surface area per unit mass, SA) increases the overall reaction rate by limiting the passivating feedbacks of the PL and ML. The measured slag SA is sensitive to measurement method; ${ }^{22)}$ at the $\mu \mathrm{m}$ to $\mathrm{mm}$ scale the PSD and roundness are the primary features, at the nm to $\mu \mathrm{m}$ scale surface roughness and porosity $(\phi)$ are the dominant features. The contribution of $\phi$ to $\mathrm{SA}$ is dependent on the average pore diameter $\left(\phi_{D}\right)$; equivalent $\phi$ with a smaller $\phi_{D}$ necessitates a longer total pore length and a larger potential SA due to the faster increase in volume over surface area for an expanding sphere. However, the theoretical potential SA does not mirror empirical results due to incomplete connectivity of pores. Empirical results and simulations suggest that pore length is limited to $\sim 5$ times $\phi_{D}{ }^{23)}$ Porosity and $\phi_{D}$ are only sporadically reported in the slag literature; nevertheless, reported $\phi$ ranges from $\sim 5-60 \%$ and the modal $\phi_{D}$ is reported to be 10 and 20 of nm. Taking into account that the effect of $\mathrm{CO}_{2}$ mineralization is to smooth and round micromorphological features smaller than $\sim 0.2-0.4 \mu \mathrm{m}^{24)}$ while filling void spaces $<0.15 \mu \mathrm{m},{ }^{25)}$ the increase in SA of slag due to micromorphology is likely significant only during the initial reaction phase, after which the PSD is the sole feature with meaningful impact on SA.

Polettini et al. $^{26)}$ specifically evaluated the significance of particle size distribution (PSD) on slag-based $\mathrm{CO}_{2}$ mineralization; their results confirm the basic geometric logic of increased SA promoting faster overall reaction rate and increased conversion. Despite its critical importance, PSD is not appropriately quantified in most papers. Due to nongaussian size distributions that occur when grinding minerals at the micrometer-scale ${ }^{27)}$ and the effect of grinding time on PSD ${ }^{28)}$ passing sieve size ( $\left.\mathrm{D}_{\text {passing }}\right)$, volume median diameter $\left(\mathrm{D}_{50}\right)$, surface area moment mean $(\mathrm{D}[3,2])$, volume moment mean $(\mathrm{D}[4,3])$, and other summary statistics are all insufficient to determine the reaction extent for a given reaction depth, or equivalently, the reaction depth given a conversion extent. Equation (1) applies the shrinking core model to reaction extent of a population of particles, where $r_{i}$ is the radius of an individual particle, $\delta$ is the reaction depth, and $n_{i}$ is the number of particles of radius $r_{i}$. Figures 
Table 1. Gibbs energy of reaction, product layer depth, and specific comminution energy of some common slag minerals

\begin{tabular}{|c|c|c|c|c|}
\hline Mineral & $\begin{array}{c}\text { Reaction } \\
\text { depth }(\mu \mathrm{m})^{\dagger}\end{array}$ & $\begin{array}{c}S E_{I G} \\
\text { (J } \mathrm{m} / \text { tonne) }\end{array}$ & $\begin{array}{c}S E_{G B} \\
\text { (J } \mathrm{m} / \text { tonne) }\end{array}$ & $\begin{array}{c}S E_{I P} \\
(\mathrm{~J} \mathrm{~m} / \text { tonne) }\end{array}$ \\
\hline $\mathrm{MgO}^{\ddagger}$ & $1.322-7.594$ & 34.485 & 30.918 & 27.352 \\
\hline $\mathrm{CaO}$ & - & 22.417 & 19.855 & 17.293 \\
\hline $\mathrm{FeO}$ & - & 8.580 & 7.718 & 6.857 \\
\hline $\mathrm{Fe}_{3} \mathrm{O}_{4}$ & - & 10.599 & 9.349 & 8.100 \\
\hline $\mathrm{MgFe}_{2} \mathrm{O}_{5}$ & - & 18.112 & 16.583 & 15.055 \\
\hline $\mathrm{Ca}_{2} \mathrm{Fe}_{2} \mathrm{O}_{5}{ }^{\ddagger}$ & $1.544-8.474$ & 19.713 & 18.043 & 16.373 \\
\hline $\mathrm{MgAl}_{2} \mathrm{O}_{4}$ & - & 35.175 & 31.825 & 28.474 \\
\hline $\mathrm{Ca}_{3} \mathrm{Al}_{2} \mathrm{O}_{6}$ & - & 30.873 & 28.174 & 25.475 \\
\hline $\mathrm{Ca}_{12} \mathrm{Al}_{14} \mathrm{O}_{33}$ & - & 36.523 & 33.388 & 30.254 \\
\hline $\mathrm{Ca}_{4} \mathrm{Al}_{2} \mathrm{Fe}_{2} \mathrm{O}_{10}$ & - & 26.501 & 24.181 & 21.862 \\
\hline$\alpha-\mathrm{SiO}_{2}$ & NA & 17.055 & 14.718 & 12.381 \\
\hline $\mathrm{SiO}_{2}{ }^{\mathrm{a}}$ & NA & 29.075 & 27.388 & 25.701 \\
\hline $\mathrm{SiO}_{2}{ }^{\mathrm{b}}$ & NA & 36.486 & 34.599 & 32.713 \\
\hline $\mathrm{Mg}_{2} \mathrm{SiO}_{4}$ & - & 17.655 & 15.558 & 13.461 \\
\hline $\mathrm{Mg}_{2} \mathrm{Si}_{2} \mathrm{O}_{6}$ & - & 14.495 & 12.599 & 10.703 \\
\hline $\mathrm{CaSiO}_{3}{ }^{\mathrm{c}, \S}$ & 0.197 & 20.192 & 17.771 & 15.351 \\
\hline $\mathrm{CaSiO}_{3}{ }^{\mathrm{d}}$ & - & 20.461 & 17.982 & 15.503 \\
\hline $\mathrm{Ca}_{3} \mathrm{Si}_{2} \mathrm{O}_{7}^{\S}$ & 3.338 & 20.845 & 18.406 & 15.966 \\
\hline $\mathrm{Ca}_{2} \mathrm{MgSi}_{2} \mathrm{O}_{7}^{\ddagger}$ & $0.631-4.319$ & 18.031 & 15.771 & 13.511 \\
\hline$\beta-\mathrm{Ca}_{2} \mathrm{SiO}_{4}^{\S}$ & $\geq 7.202$ & 14.993 & 13.005 & 11.018 \\
\hline$\gamma-\mathrm{Ca}_{2} \mathrm{SiO}_{4}^{\S}$ & $\geq 12.931$ & 15.227 & 13.240 & 11.253 \\
\hline $\mathrm{CaMgSiO}_{4}$ & - & 16.388 & 14.342 & 12.296 \\
\hline $\mathrm{Ca}_{3} \mathrm{MgSi}_{2} \mathrm{O}_{8}^{*}$ & $0.306-2.314$ & 15.833 & 13.771 & 11.709 \\
\hline $\mathrm{Ca}_{7} \mathrm{MgSi}_{4} \mathrm{O}_{16}{ }^{\ddagger}$ & $1.544-8.474$ & 12.153 & 10.441 & 8.729 \\
\hline $\mathrm{CaFeSiO}_{4}$ & - & 11.919 & 10.331 & 8.742 \\
\hline $\mathrm{Ca}_{3} \mathrm{SiO}_{5}^{\S}$ & $\geq 16.845$ & 20.883 & 18.560 & 16.236 \\
\hline $\mathrm{Fe}_{2} \mathrm{SiO}_{4}$ & - & 9.499 & 8.228 & 6.958 \\
\hline $\mathrm{Mg}_{3} \mathrm{Al}_{2} \mathrm{Si}_{3} \mathrm{O}_{12}$ & - & 20.060 & 17.632 & 15.203 \\
\hline $\mathrm{Ca}_{3} \mathrm{Al}_{2} \mathrm{Si}_{3} \mathrm{O}_{12}$ & - & 34.569 & 31.006 & 27.444 \\
\hline $\mathrm{Ca}_{2} \mathrm{Al}_{2} \mathrm{SiO}_{7}$ & - & 27.716 & 24.883 & 22.051 \\
\hline $\mathrm{CaAl}_{2} \mathrm{Si}_{2} \mathrm{O}_{8}$ & - & 23.459 & 20.691 & 17.924 \\
\hline $\mathrm{Al}_{2} \mathrm{SiO}_{5}$ & NA & 34.121 & 30.958 & 27.796 \\
\hline $\mathrm{Al}_{6} \mathrm{Si}_{2} \mathrm{O}_{13}$ & NA & 28.212 & 25.192 & 22.173 \\
\hline $\mathrm{CaCO}_{3}{ }^{\mathrm{e}}$ & NA & 12.957 & 11.613 & 10.270 \\
\hline $\mathrm{CaCO}_{3}{ }^{\mathrm{f}}$ & NA & 8.561 & 7.777 & 6.994 \\
\hline $\mathrm{CaCO}_{3}{ }^{\mathrm{g}}$ & NA & 13.229 & 11.807 & 10.384 \\
\hline $\mathrm{MgCO}_{3}$ & NA & 16.286 & 14.728 & 13.170 \\
\hline
\end{tabular}

$\dagger$ Reaction depth was calculated based on $\mathrm{CO}_{2}$ mineralization extent and PSD using the shrinking core model. Bodor et al. did not include PSD information, so the range of PSD from Ashraf and Olek were used.

$\$$ Data from Bodor et al. ${ }^{20)}$ Experimental conditions: incubator reactor, $30^{\circ} \mathrm{C}$, atm. pres., $95 \%$ humidity, $20 \% \mathrm{CO}_{2}$

$\S$ Data from Ashraf and Olek. ${ }^{21)}$ Experimental conditions: incubator reactor, $35^{\circ} \mathrm{C}$, atm. pres., $94 \%$ humidity, $15 \% \mathrm{CO}_{2}$

a: Tridymite; b: Cristobalite; c: Pseudowollastonite; d: Wollastonite; e: Calcite; f: Aragonite; g: Vaterite 1(a) and 1(b) illustrate the effect of using summary statistics instead of the complete PSD on calculated reaction extent and reaction depth, respectively.

\section{Conversion extent $=$}

$$
\begin{aligned}
& \sum_{n_{i} \geq \delta}^{n_{i}=r_{\max }}\left\{\left[\frac{r_{i}^{3}-\left(r_{i}-\delta\right)^{3}}{r_{i}^{3}}\right] \times\left(\frac{\frac{4}{3} \pi r_{i}^{3} n_{i}}{\sum_{r_{i}=r_{\min }}^{n_{i}=r_{\max }} \frac{4}{3} \pi r_{i}^{3} n_{i}}\right)\right\} \\
& +\sum_{r_{i}=r_{\min }}^{r_{i}<\delta}\left(\frac{\frac{4}{3} \pi r_{i}^{3} n_{i}}{\sum_{r_{i}=r_{\min }}^{r_{i}=r_{\max }} \frac{4}{3} \pi r_{i}^{3} n_{i}}\right)
\end{aligned}
$$

\subsection{Mineral Locking}

As is discussed in Section 3.1, when slag is solidified in a time frame of 10's of seconds to 10's of minutes (e.g., water impingement, pit cooling), a large number of distinct minerals may concurrently nucleate and grow into one another. The ultimate effect is mineral locking (ML), the blocking of highly reactive species from taking part in $\mathrm{CO}_{2}$ miner-
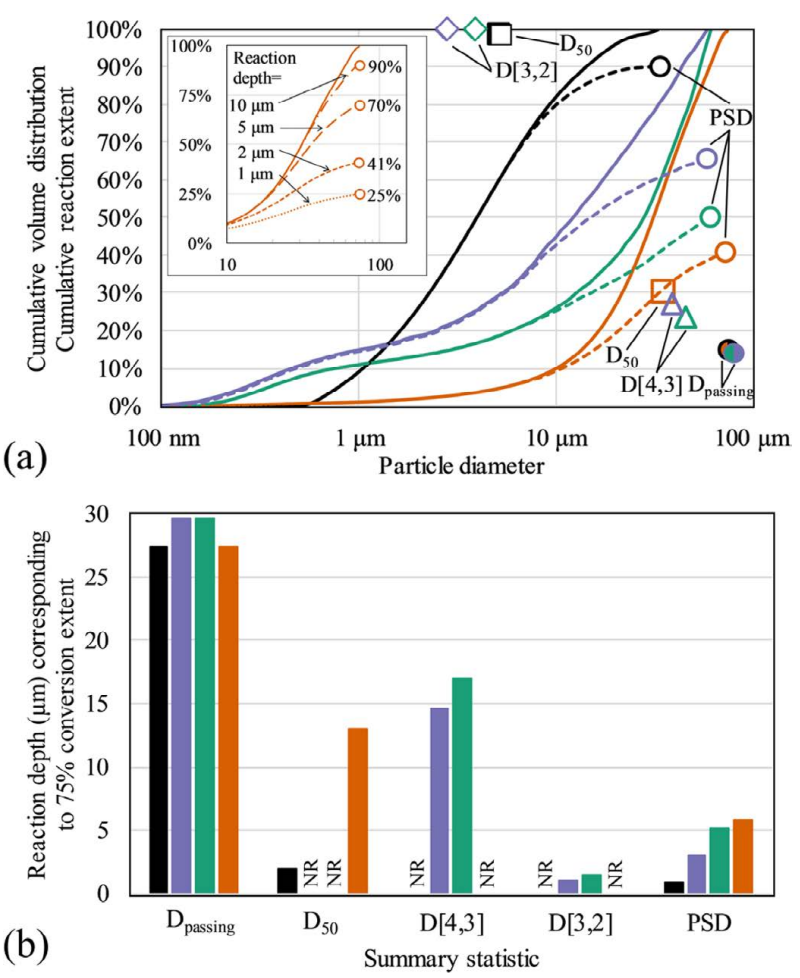

Fig. 1. Disparate results due to using summary statistics as opposed to the complete PSD when calculating reaction extent or reaction depth across a population of particles with the shrinking core model. Figure 1(a) plots the calculated conversion extent assuming an uniform reaction depth of $2 \mu \mathrm{m}$. Solid lines are the PSD represented as a cumulative volume distribution. Dashed lines are the cumulative reaction extent calculated using the entire PSD. The inset shows the effect of reaction depth when applied using the PSD with the shrinking core model. Figure 1(b) shows the calculated reaction depth for a population reaction extent of $75 \%$. The PSD and summary statistics are those reported in Ashraf and Olek ${ }^{21)}$ (black and orange data) and Santos et al. ${ }^{29)}$ (purple and green data). 'NR' indicates the data was not reported in the source papers. (Online version in color.) 
alization by less reactive species. Probability and geometry dictate that the passivating effects of ML will increase as the number and variety of mineral grains increases. To quantify the effect of ML, a binary compound slag was simulated using a two-dimensional Voronoi cell-based Monte Carlo analysis (VCMC). The Voronoi cells are representative of nucleated grains and the simulation space is representative of a single slag grain. By altering the number of Voronoi cells $\left(n_{V C}\right)$, the ratio $(\Omega)$ of the particle diameter to the average grain diameter $(\phi)$ was modified. In this way, the effect of grain size and grinding extent on ML was evaluated. Additionally, the concentration of the reactive species $\left(c_{R}\right)$ was varied to assess effects on ML. The Voronoi cell-generating point coordinates were assigned via random number generator to mimic the stochastic nature of nucleation. ML extent was calculated as the area percentage of reactive species that did not directly contact the outer surface or were not connected via reactive cells to the outer surface. Each test condition (i.e., $\Omega$ and $c_{R}$ ) was run 10 times or until the $90 \%$ confidence interval $<5 \%$, whichever was larger, to obtain estimates of population-level ML. Figure 2(a) displays the results of the VCMC and Fig. 2(b) displays several of the VCMC simulations for qualitative understanding. The results in agreement with intuition: namely, ML increases as $\Omega$ increases and as $c_{R}$ decreases. Moreover, at high enough concentrations (i.e., $c_{R} \approx 60 \%$ ) the interconnectedness of grains essentially eliminates ML effects. As the VCMC is two dimensional and does not take into account ML that arises from the PL, these results should be considered as illustrative of the magnitude of the ML effect, but not neces-
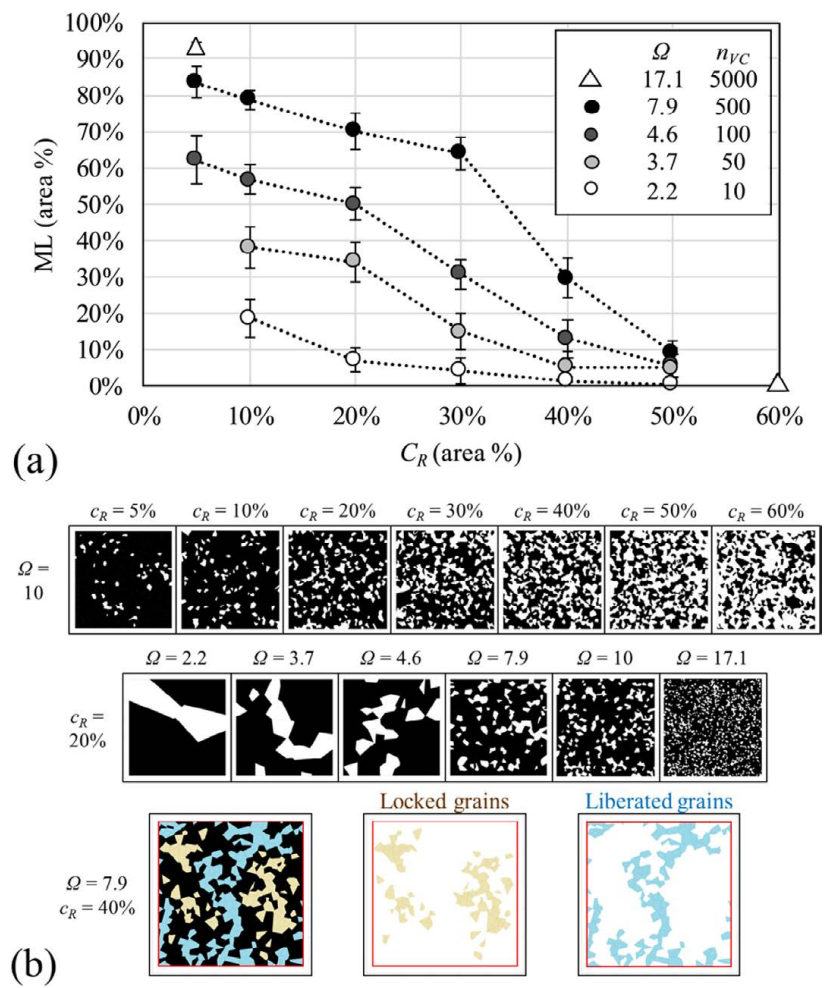

Fig. 2. The effect of ML as a function of the ratio $(\Omega)$ of particle size to grain size and the concentration $\left(c_{R}\right)$ of reactive species (a) as calculated by 2D Voronoi cell-based Monte Carlo simulation. (b) Example Voronoi cell simulations showing the effects of increasing $c_{R}$ and increasing $\Omega$. (Online version in color.) sarily quantitatively accurate.

\subsection{Grinding Energy}

Aside from a few examples, ${ }^{12,30)}$ there is vanishingly little discussion of the energy required to grind slag to the 10's of $\mu \mathrm{m}$ used in most processes. When present, calculations of grinding energy are decidedly unsophisticated, limited to application of notoriously unreliable empirical fits (e.g., Bond's Work Index) to minerals or scales not covered in the dataset. Grinding energy is dependent on material-specific parameters (e.g., mineralogy, crystallinity, micromorphology, PSD) and equipment-specific parameters (e.g., force application mechanism, energy loss to heat, noise, plastic deformation). Due to these complications, estimation of grinding energy across a wide range of minerals has historically eluded accurate computation. Tromans and Meech developed a first-principles calculation of the critical stress intensity for crack propagation and the accompanying energy release based solely on the microscale mineralogy and structure of the material. ${ }^{31,32)}$ Equation (2) calculates the minimum energy, equivalent to change in surface energy per unit mass $(\triangle S E, \mathrm{~J} / \mathrm{kg})$, required for the grinding a mass of particles of initial diameter $\left(D_{i}, \mathrm{~m}\right)$ to a final diameter $\left(D_{f}\right.$, m) based on material density $\left(\rho, \mathrm{kg} / \mathrm{m}^{3}\right)$, surface roughness $\left(F_{r}\right.$, unitless), and surface energy $\left(\gamma, \mathrm{J} / \mathrm{m}^{2}\right)$. The surface roughness, $F_{r}$, is not expected to vary significantly between populations of particles, meaning the comminution energy is proportional to $\gamma / \rho$. The surface energy, $\gamma$, is dependent on the mineral in question, whether it is crystalline or amorphous, and whether the fracture is intragranular (IG), occurs at a grain boundary (GB), or is between disparate minerals ('interphase', IP). The surface energies, $\gamma_{I G}$ and $\gamma_{G B}$, are one half the associated crack energy release $\left(G_{I G}\right.$ or $\left.G_{G B}\right)$ which are calculated via Eqs. (3) and (4), respectively. The interphase surface energy $\gamma_{I P}$ is calculated equivalently to $\gamma_{G B}$ but with modifications described below.

$$
\begin{aligned}
& \Delta S E=\frac{6 F_{r} \gamma}{\rho}\left(\frac{1}{D_{f}}-\frac{1}{D_{i}}\right) \\
& G_{I G}=\left[\left(\frac{1-2 v}{3}\right)\left(N^{2 / 3} M_{\alpha}\right)\left(\frac{e^{2}}{4 \pi \varepsilon_{0}}\right)\left(\frac{R_{0}{ }^{n-1}}{n \times R_{x}^{n}}-\frac{1}{R_{x}}\right)\right]_{R_{x}=R_{0}}^{R_{x}=R_{\text {limit }}} \\
& \begin{array}{l}
G_{G B}=\left[\left(\frac{1-2 v}{3}\right)\left(N^{2 / 3} M_{\alpha}\right)\left(\frac{e^{2}}{4 \pi \varepsilon_{0}}\right)\right] \\
\times\left\{\left[f\left(\frac{R_{0}{ }^{n-1}}{n \times R_{x}^{n}}-\frac{1}{R_{x}}\right)\right]_{R_{x}=R_{0}}^{R_{x}=R_{\text {limit }}}+\left[(1-f)\left(\frac{R_{0}{ }^{n-1}}{n \times R_{x}^{n}}-\frac{1}{R_{x}}\right)\right]_{R_{x}=m R_{0}}^{R_{x}=R_{\text {limit }}}\right\}
\end{array} \\
& n=1+\frac{3 E R_{0}^{4}}{(1-2 v) M_{\alpha}}\left(\frac{4 \pi \varepsilon_{0}}{e^{2}}\right)
\end{aligned}
$$

Poisson's ratio is denoted by $v, N$ is the atomic density of the unstrained crystal $\left(1 / \mathrm{m}^{3}\right), M_{\alpha}$ is the combined Madelung constant $\left(=\alpha^{2} M / a_{n}\right.$; where $\alpha$ is the largest common valence on ions, $M$ is the Madelung constant, and $a_{n}$ is the stoichiometric number of atoms per molecule; unitless), $e$ is 
the elementary charge $\left(1.602177 \times 10^{-17} \mathrm{C}\right), \varepsilon_{0}$ is the permittivity in vacuum $\left(8.854188 \times 10^{-12} \mathrm{~F} / \mathrm{m}\right), \mathrm{R}_{0}$ is the average distance between atoms in the unstrained crystal $(\mathrm{m}), R_{x}$ is the average distance between atoms in the $x$-direction due to a tensile stress in the $x$-direction $(\mathrm{m}), R_{\text {limit }}$ is equal to $R_{0}+$ $2 \times 10^{-9}(\mathrm{~m}), f$ is the area fraction of grain boundary coincident sites ( $=0.5$ for GB, $=0$ for IP), and $m$ is a multiplying factor related to the distance between atoms at the grain boundary (=1.5 for GB and IP). The unitless parameter $n$ is related to the bulk modulus of elasticity and is calculated using Eq. (5), where $E$ is the equilibrium tensile elastic modulus $(\mathrm{Pa})$.

The predictions of Tromans and Meech results in industrial comminution efficiency of $\sim 1 \%$ when grinding to $40 \mu \mathrm{m}$, consistent with the findings of empirical studies. ${ }^{28)}$ Table 1 lists the material specific, theoretical minimum comminution energies of common compounds in fresh and carbonated slag as calculated by Eqs. (2)-(5). Material properties necessary for calculation were gleaned from the work of Vieillard ${ }^{33)}$ and 'The Materials Project'. ${ }^{34)}$ The basic trend of fracture energy is $\mathrm{IG}>\mathrm{GB}>\mathrm{IP}$, with $\mathrm{GB} \approx 0.89$ $\mathrm{IG}$ and $\mathrm{IP} \approx 0.88 \mathrm{~GB}$.

In homogeneously solidified slag (i.e., amorphous structure), all fractures are IG as there are no grain boundaries. For amorphous solids a correction factor must be applied to account for the inherent ductility of the structurally disordered material. Comparison of the results of Wang et al. ${ }^{35)}$ with Tromans and Meech indicate a consistent increase in fracture energy for silica, sodium silicate, and calcium aluminosilicate glasses over $G_{I G}, G_{G B}$, and $G_{I P}$ of $\sim 1.63, \sim 1.78$, and $\sim 1.96$, respectively; this covers the entire structural landscape of silicate glasses. These theoretical results are consistent with the result of Purwanto et al. which found fracture of RCA slag (amorphous) required $\sim 1.82$ times more energy than water-impinged slag (ostensibly a mixture of IG, GB, and IP fractures). ${ }^{36)}$ In slags solidified moderately quickly (e.g., water impinged, pit cooled), the polycrystalline structure results in the potential for IP, GB, and IG fractures. Though grain boundaries are plentiful, there is a random distribution in the alignment of grain boundaries to the application of force. This trait, combined with the short transgranular distance of polycrystalline slags, suggests a mix of IG, GB, and IP fractures will occur. In slowly solidified slag grains are much larger, resulting in IP and GB being the dominate fracture mechanism until exhausted. However, the GSD of such slags is typically larger than the necessary PSD for $\mathrm{CO}_{2}$ mineralization, meaning IG grinding would be necessary for further size reduction.

Using the Eqs. (6)-(9) and the results from Table 1, general energetic guidelines for operating a slag-based $\mathrm{CO}_{2}$ mineralization process can be derived for a given mineral considering the region-specific $\mathrm{CO}_{2}$ intensity of energy generation. This paper focusses on mild operating conditions to obtain $\mathrm{CO}_{2}$ mineralization, but does require a high concentration and purity $\mathrm{CO}_{2}$ source. The $\mathrm{CO}_{2}$ associated with separating and purifying $\mathrm{CO}_{2}$ for mineralization is accounted for in Eq. (8).

\section{$\mathrm{CO}_{2}$ reduction $=$ \\ $\mathrm{CO}_{2}$ reduction potential $-\mathrm{CO}_{2}$ separation-Grinding}

$\mathrm{CO}_{2}$ reduction potential $=\left(\frac{\mathrm{mol}_{\mathrm{Ca}}+\mathrm{mol}_{\mathrm{Mg}}}{\mathrm{kg}, \text { mineral }}\right)\left(\frac{k_{\mathrm{CO}_{2}}}{\text { mol }_{\mathrm{CO}_{2}}}\right) \ldots$

$$
\mathrm{CO}_{2} \text { separation }=\left(\frac{k W h}{k g_{\text {separated } \mathrm{CO}_{2}}}\right)\left(\frac{k g_{\mathrm{CO}_{2} \text {,released }}}{k W h_{\text {utility-scale generation }}}\right)
$$

$$
\begin{aligned}
& \text { Grinding }=S E\left(\frac{1}{D_{f}}-\frac{1}{D_{i}}\right) \\
& \text { (equipment efficiency) }\left(\frac{\mathrm{kg}_{\mathrm{CO}_{2}, \text { released }}}{k W h_{\text {utility-scale generation }}}\right)
\end{aligned}
$$

The energy to separate and purify $\mathrm{CO}_{2}$ from power plants was assumed to be $402 \mathrm{~kJ} / \mathrm{kgCO}_{2}{ }^{37)}$ The current $\mathrm{CO}_{2}$ intensity of energy generation for the major ISM regions is: China $=0.681$, OECD Asia $=0.561$, OECD Americas $=0.441$, and $\mathrm{OECD}$ Europe $\left.=0.311 \mathrm{kgCO}_{2} / \mathrm{kWh}\right){ }^{6}{ }^{6}$ For polycrystalline slag, the mineral-specific grinding energy was assumed to be the average of IG, GB, and IP fractures. An equipment efficiency of 1\% was assumed for all fractures. Figure 3(a) plots the net $\mathrm{CO}_{2}$ reduction potential for several major slag minerals as a function of $D_{f}$. Figure $3(\mathrm{~b})$ plots the net $\mathrm{CO}_{2}$ reduction potential for $\beta-\mathrm{Ca}_{2} \mathrm{SiO}_{4}$ and $\mathrm{CaAl}_{2} \mathrm{Si}_{2} \mathrm{O}_{8}$ in the four major ISM markets. These plots represent the depletion of $\mathrm{CO}_{2}$ reduction potential due to supplying $\mathrm{CO}_{2}$ and grinding energy, and do not take into account the aforementioned issues of ML and PL, nor is operation of ancillary equipment considered.
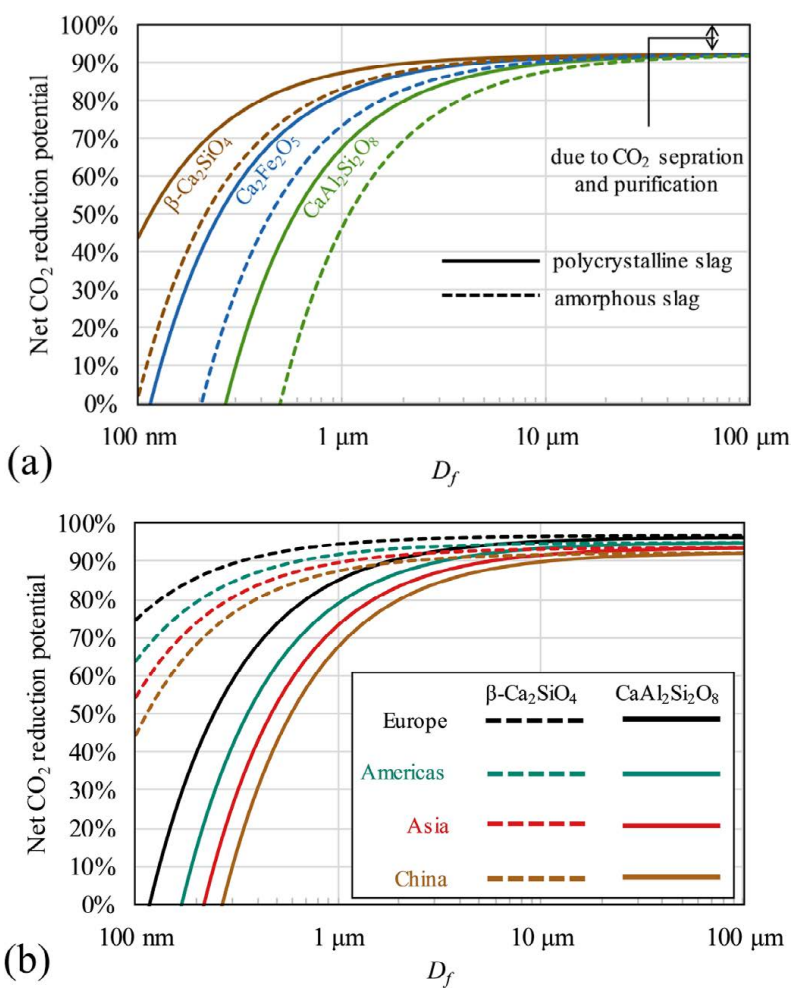

Fig. 3. Net $\mathrm{CO}_{2}$ reduction potential vs. $D_{f}$ (a) dependency on slag mineralogy and crystallinity, (b) dependency on the $\mathrm{CO}_{2}$ intensity of energy generation in the major ISM regions. (Online version in color.) 


\section{Effects of Solidification and Cooling on Slag Charac- teristics}

\subsection{Solidification}

Slag emerges from the ISM process as a molten melt, usually well above its compositionally-dependent liquidus temperature $\left(T_{L}\right)$. As it cools, the formation of solid nuclei becomes thermodynamically favored as described by Eq (10), where $\Delta G$ is the excess Gibbs Free Energy between the melt and nucleating solid, $\gamma_{S}$ is the surface energy, $L$ is the latent heat of fusion, $T$ is the temperature, and $\theta$ is the contact angle between the nucleating solid and a surface. In the case of nucleation occurring in the bulk melt, $\theta$ is $180^{\circ}$ and the third bracket reaches its maximum value of 1 . This strong dependence of $\Delta G$ on the shape of a nucleating solid is reflected in the fact that the vast majority of ISM slag undergoes solidification instigated at boundaries with equipment (heterogenous solidification). From Eq. (10), the driving force of solidification is dependent on the undercooling $\left(T_{U}=T_{L}-T\right)$ of the melt. Likewise, the radius of a nucleating solid $(r)$ that is stable against re-melting, and the steady-state nucleation rate $(N)$ of said nuclei are temperature dependent, as shown in Eqs. (11) and (12).

$$
\begin{aligned}
& \Delta G=\left(\frac{16 \pi \gamma_{S}^{3} T_{L}^{2}}{3 L^{2}}\right)\left\{\frac{1}{\left(T_{L}-T\right)^{2}}\right\}\left\{\frac{(2+\cos \theta)(1-\cos \theta)^{2}}{4}\right\} \\
& r=\left(\frac{2 \gamma_{S} T_{L}}{L}\right)\left(\frac{1}{T_{L}}\right) \\
& N=f_{0} C_{0} \exp \left(\frac{-\Delta G}{k T}\right)
\end{aligned}
$$

In Eq. (12), $f_{0}$ is the frequency of an atom attaching to the stable nuclei, $C_{0}$ is the number of atoms per unit volume, and $k$ is the Boltzmann constant. The aggregation of molecules is a stochastic process and thus has an average lag time $(\tau)$ before an adequate number of molecules amass into a thermodynamically stable nucleus. The lag time, $\tau$, is compositionally- and temperature-dependent. Equation (13) calculates $\tau$ per the method of Mokshin and Galimzyanov, ${ }^{38)}$ where $\tau_{g}$ is the lag time at the glass transition temperature, $\tilde{T}_{g}$ is the normalized glass transition temperature, $\tilde{T}$ is the normalized temperature of interest, and $\varepsilon$ is a dimensionless factor that accounts for the ability of a material to maintain structural disorder.

$$
\tau=\tau_{g}\left(\frac{\tilde{T}_{g}}{\tilde{T}}\right)^{\varepsilon}
$$

The dependence of mineralogy and GSD on $T_{U}$ is complex. When slowly solidified (small $T_{U}$ ), nucleation events are rare, allowing for a nucleated mineral to grow through the melt without physical or chemical interactions from other growing minerals. As a result, a small number of simple oxides, with large grain sizes, are observed in slowly solidifying slags. ${ }^{39)}$ Additionally, the large supply of thermal energy allows for restructuring of solids into thermodynamically favorable mineralogies and geometries. As $T_{U}$ increases, the number of solid nuclei and the compo- sitional variety of nucleating minerals increases. Minerals that are not compositionally-equivalent to the bulk melt alter the elemental composition of the adjacent melt as they grow. The local change in melt composition in turn alters the landscape of potential minerals that can nucleate; ${ }^{40}$ this phenomenon explains the small GSD, large variety of minerals, and high degree of ML that is observed in slags solidified under moderate $T_{U}$ (e.g., pit cooling). When slag is homogeneously solidified, the local mineral composition is essentially isotropic and individual grains are absent.

For nucleation lag time, $\tau$, the increase in $\Delta G$ due to increased undercooling (i.e., small to moderate $T_{U}$, or moderate to large $T_{U}$ ) is more substantial than the reduced kinetic energy concomitant with temperature decrease, resulting in a decrease in $\tau$. However, as $T_{U}$ increases the kinetic barrier eventually prevents the arrangement of molecules into thermodynamically-favorable geometries, delaying solidification until the entire melt becomes thermodynamically predisposed to solidify. This 'homogeneous' solidification generates a solid slag without long range atomic order, socalled 'amorphous' or 'glassy' slag. The large $T_{U}$ required for homogeneous solidification also drives heat transfer, which in turn reduces the $T_{U}$. Due to this feedback, homogeneous solidification is only successfully applied to small slag volume such as the $<2 \mathrm{~mm}$ diameter particles produced in the rotary cup atomization method (RCA). ${ }^{41)}$ Examination of water-impinged slag indicates it is not truly amorphous, ${ }^{39}$ ) but rather polycrystalline with grain sizes on the order of a few micrometers; nevertheless, the rapid cooling suppresses the transition of $\beta-\mathrm{Ca}_{2} \mathrm{SiO}_{4}$ to $\gamma-\mathrm{Ca}_{2} \mathrm{SiO}_{4}$, making waterimpinged slags suitable for use as ggbs.

In addition to mineralogy and GSD, the $\phi$ of slag is affected by the solidification conditions. Rapid solidification methods involving water tend to result in very high $\phi$ slags regardless of the process details, ${ }^{42)}$ whereas the $\phi$ in air cooled slags is sensitive to the equipment. ${ }^{43)}$ The porosity, $\phi$, is dictated by the exclusion of gas from the solid phase upon phase transition from liquid to solid, followed by nucleation of gas pores, Ostwald ripening of the pores, and growth along grain boundaries when present. In general, longer solidification times lead to larger $\phi_{D}$, longer pore networks, and lower pore network tortuosity.

\subsection{Cooling}

The high solidus temperature of ISM slags imbues solid slag with substantial thermal energy that can potentially alter its structure and micromorphology. The thermal energy content of $\mathrm{Ca}_{2} \mathrm{SiO}_{4}$ from $1300 \mathrm{~K}$ to $300 \mathrm{~K}$ is $\sim 316 \mathrm{~kJ} / \mathrm{kg}$. ${ }^{44}$ ) For slag cooled via natural convection (e.g., pit cooling), this inherent thermal energy is sufficient to restructure $\beta-\mathrm{Ca}_{2} \mathrm{SiO}_{4}$ to $\gamma-\mathrm{Ca}_{2} \mathrm{SiO}_{4}{ }^{45)}$ More rapid cooling, as occurs in heat recovery and quenching methods, prevents this phase transition. ${ }^{46)}$

The mineralogy, structure, and micromorphology set by the solidification process controls what micromorphological changes are possible during cooling. In homogeneously solidified slag, the thermophysical properties are isotropic and, owing to the amorphous structure, generally resistant to thermal restructuring into crystalline structures ${ }^{47)}$ or thermally-induced fracturing. ${ }^{48)}$ When slag is solidified more slowly, the appearance of distinct, mineral grains means that 
structural (e.g., $\beta$ - to $\gamma-\mathrm{Ca}_{2} \mathrm{SiO}_{4}$ phase transition) and micromorphological (e.g., micro-scale fracturing) alterations are possible. Phase transition requires slow cooling such that sufficient time and energy is available for structural rearrangement of atoms. On the other hand, micro-scale fracturing requires rapid cooling such that large thermal gradients exist between adjacent portions of the slag. The thermal stress $\left(\sigma_{t}\right)$ within slag is given by Eq. (14), where $\Delta T$ is the temperature difference, $\alpha$ is the linear coefficient of thermal expansion, $E$ is Young's modulus, $\lambda$ is the relaxation time, and $K$ is the relaxation parameter. Due to differences in thermal conductivity $(\kappa)$ and $\alpha$, thermally-induced stresses are particularly large at the grain boundaries of distinct minerals. In previous work, the authors demonstrated that quenching of high temperature, solid slag can generate fractures throughout a polycrystalline $\mathrm{Ca}_{2} \mathrm{SiO}_{4}$ network, especially at boundaries between disparate minerals. ${ }^{49)}$ According to simulations mimicking the experimental conditions (i.e., $1173 \mathrm{~K}, 3.6 \mathrm{~mm}$ diameter $\mathrm{Ca}_{2} \mathrm{SiO}_{4}$ quenched in $293 \mathrm{~K}$ water), the energy available to induce fractures in slag was $\sim 88 \mathrm{~J} / \mathrm{g}$, slag, after accounting for energy transfer to heat and vaporize water, and the fact that thermal stress exceeded fracture stress only during the first few milliseconds of quenching. This rapid moderation of thermal stresses with quenching explains why water-impingement of molten slag fails to generate large quantities of microfractures.

$$
\sigma_{t}=\Delta T \alpha E e^{\left(\frac{-\lambda E}{K}\right)}
$$

\section{Theoretical Effect of Solidification and Cooling on Slag-based $\mathrm{CO}_{2}$ Mineralization Efficiency}

Estimation of the magnitude of the effect of the solidification and cooling processes on the net $\mathrm{CO}_{2}$ reduction of slag-based $\mathrm{CO}_{2}$ mineralization was performed. The analysis was confined to industry average ironmaking and steelmaking slag compositions. ${ }^{15)}$ Solidification conditions were grouped into homogeneous (e.g., RCA), large $T_{U}$ (e.g., water impingement), moderate $T_{U}$ (e.g., pit cooling), and small $T_{U}$ (c.f. Gautier et al.). Cooling time from solidus temperature to ambient temperature was set as seconds (quench), minutes (heat recovery), and hours (natural cooling). The mineralogical composition for steel slags was based on the work of Gautier et $a l^{39)}$ and extended to iron slags using assumptions based on the underlying physical mechanisms as discussed in this paper. The effects of quenching on micromorphology were based on previously published work. ${ }^{49)}$ Due to a lack of empirical data, $\phi$ was not considered. The final grind diameter, $D_{f}$, was set such that complete conversion of $\mathrm{Ca}$ and $\mathrm{Mg}$ to carbonates was assured. The grain size $(\phi)$ and concentration for each mineral was used to determine the $D_{f}$ range necessary to keep ML to $<5 \%$ using the results summarized in Fig. 2(a). The $D_{f}$ range was separately calculated as twice the mineral-specific reaction depth. The $D_{f}$ range with the smaller values was set as the $D_{f}$ range for all minerals within the slag. When $\phi>D_{f}$, the $\phi$ was used to set the diameter at which a change in fracture mechanism occurs $\left(D_{m}\right)$ for each mineral. The grinding energy for each condition was calculated using Eq. (9) with the mineral specific grinding energy from Table 1 . Given the range of values for $\phi, D_{i}, D_{m}$, and $D_{f}$, a Monte Carlo analysis was performed to determine the overall fracture energy for each solidification and cooling condition. Each condition was run 5000 times, with a normal distribution being produced from the values listed for each of the parameters in Table 2. The values listed represent the 10th and 90th percentile when generating the normal distributions, but were also used as the limiting values for calculating the minimum and maximum potential grinding energy, in order to filter outlier results

Table 2. Conditions and values used in the analysis of the effect of solidification and cooling methods on iron and steel slag-based $\mathrm{CO}_{2}$ mineralization efficiency. Estimated comminution energy to achieve full conversion of each slag under the given solidification and cooling conditions is also shown.

\begin{tabular}{|c|c|c|c|c|c|c|c|c|c|}
\hline & $\begin{array}{c}\text { Solidification } \\
\text { type }\end{array}$ & $\begin{array}{c}\text { Cooling } \\
\text { type }\end{array}$ & Assumed mineralogy & $D_{\mathrm{i}}(\mu \mathrm{m})$ & $D_{m}(\mu \mathrm{m})$ & $\begin{array}{c}\phi \min \\
(\mu \mathrm{m})\end{array}$ & $D_{f}(\mu \mathrm{m})$ & $\begin{array}{c}\text { Fracture } \\
\text { mechanism }\end{array}$ & $\begin{array}{c}\text { Grinding } \\
\text { energy mean, } \\
\text { median }(\mathrm{kJ} / \mathrm{kg})\end{array}$ \\
\hline \multirow{4}{*}{ 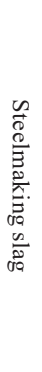 } & Homogeneous & Heat recovery & Amorphous $\left\{\mathrm{Ca}_{2} \mathrm{Fe}_{2} \mathrm{O}_{5}-\mathrm{CaSiO}_{3}\right\}(100 \%)$ & $\begin{array}{l}800- \\
2000\end{array}$ & NA & NA & $0.4-16.9$ & IG with correction factor & 5763,3698 \\
\hline & Large $T_{U}$ & Heat recovery & $\beta-\mathrm{Ca}_{2} \mathrm{SiO}_{4}(50 \%), \mathrm{Ca}_{2} \mathrm{Fe}_{2} \mathrm{O}_{5}(50 \%)$ & $\begin{array}{c}3000- \\
5000\end{array}$ & NA & 2 & $2.8-13.8$ & $\overline{\mathrm{IG}, \mathrm{GB}, \mathrm{IP}}\left(D_{i} \rightarrow D_{f}\right)$ & 2175,1953 \\
\hline & Moderate $T_{U}$ & $\begin{array}{l}\text { Quench } \\
\text { Heat recovery } \\
\text { Natural }\end{array}$ & $\begin{array}{l}\text { Silicates }(50 \%), \mathrm{Ca}_{2} \mathrm{Fe}_{2} \mathrm{O}_{5}(20 \%) \\
\quad \mathrm{CaO}(15 \%), \mathrm{MgFe}_{2} \mathrm{O}_{5}(15 \%)\end{array}$ & $\begin{array}{l}5000- \\
10000\end{array}$ & $33-67$ & 5 & $6.2-13.2$ & $\begin{array}{l}\overline{\mathrm{IG}, \mathrm{GB}, \mathrm{IP}}\left(D_{i} \rightarrow D_{m}\right) \\
\mathrm{IG}\left(D_{m} \rightarrow D_{f}\right)\end{array}$ & $\begin{array}{l}2018,1939 \\
2020,1940 \\
2020,1940\end{array}$ \\
\hline & Small $T_{U}$ & $\begin{array}{l}\text { Quench } \\
\text { Heat recovery } \\
\text { Natural }\end{array}$ & $\begin{array}{c}\mathrm{Ca}_{2} \mathrm{SiO}_{4}(50 \%), \mathrm{Ca}_{2} \mathrm{Fe}_{2} \mathrm{O}_{5}(45 \%) \\
\operatorname{MgO}(5 \%)\end{array}$ & 3600 & $\begin{array}{c}95-185 \\
124-224 \\
41-89\end{array}$ & 20 & $2.6-15.2$ & $\begin{array}{l}\mathrm{IG}\left(D_{m} \rightarrow D_{f}\right) \\
\mathrm{IP}\left(D_{i} \rightarrow D_{m}\right), \mathrm{IG}\left(D_{m} \rightarrow D_{f}\right) \\
\mathrm{IP}\left(D_{i} \rightarrow D_{m}\right), \mathrm{IG}\left(D_{m} \rightarrow D_{f}\right)\end{array}$ & $\begin{array}{l}1648,1500 \\
2266,2137 \\
2153,1943\end{array}$ \\
\hline \multirow{4}{*}{ 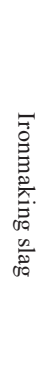 } & Homogeneous & Heat recovery & Amorphous $\left\{\mathrm{Ca}_{2} \mathrm{Al}_{2} \mathrm{SiO}_{7}-\mathrm{CaSiO}_{3}\right\}(100 \%)$ & $\begin{array}{l}800- \\
2000\end{array}$ & NA & NA & $0.4-16.9$ & IG with correction factor & 6788,4319 \\
\hline & Large $T_{U}$ & Heat recovery & Silicates (76\%), Aluminosilicates (24\%) & $\begin{array}{c}3000- \\
5000\end{array}$ & NA & 2 & $2.8-13.8$ & $\overline{\mathrm{IG}, \mathrm{GB}, \mathrm{IP}}\left(D_{i} \rightarrow D_{f}\right)$ & 2599,2333 \\
\hline & Moderate $T_{U}$ & $\begin{array}{l}\text { Quench } \\
\text { Heat recovery } \\
\text { Natural }\end{array}$ & Silicates (76\%), Aluminosilicates (24\%) & $\begin{array}{l}5000- \\
10000\end{array}$ & $33-67$ & 5 & $6.2-13.2$ & $\begin{array}{l}\overline{\mathrm{IG}, \mathrm{GB}, \mathrm{IP}}\left(D_{i} \rightarrow D_{m}\right) \\
\mathrm{IG}\left(D_{m} \rightarrow D_{f}\right)\end{array}$ & $\begin{array}{l}2184,2081 \\
2185,2083 \\
2189,2079\end{array}$ \\
\hline & Small $T_{U}$ & $\begin{array}{l}\text { Quench } \\
\text { Heat recovery } \\
\text { Natural }\end{array}$ & $\mathrm{Ca}_{2} \mathrm{SiO}_{4}(60 \%)$, Aluminates (40\%) & 3600 & $\begin{array}{c}95-185 \\
124-224\end{array}$ & 20 & $3.1-16.9$ & $\begin{array}{l}\text { IG }\left(D_{m} \rightarrow D_{f}\right) \\
\text { IP }\left(D_{i} \rightarrow D_{m}\right), \text { IG }\left(D_{m} \rightarrow D_{f}\right) \\
\text { IP }\left(D_{i} \rightarrow D_{m}\right), \text { IG }\left(D_{m} \rightarrow D_{f}\right)\end{array}$ & $\begin{array}{l}2007,1799 \\
2313,2097 \\
2403,2161\end{array}$ \\
\hline
\end{tabular}


from the Monte Carlo analysis. The average and median values from the Monte Carlo analysis for each condition are provided in Table 2. Histograms of each solidification and cooling condition with bins set at $50 \mathrm{~J} / \mathrm{kg}$ are provided in Fig. 4. The results from the Monte Carlo analysis were used to calculate the net $\mathrm{CO}_{2}$ reduction for each solidification and cooling scheme in China and Europe using Eqs. (6)-(9). The results are summarized in Fig. 5.

Figures 4 and 5 indicate that homogeneous solidification methods may severely diminish the net $\mathrm{CO}_{2}$ reduction of slags used for $\mathrm{CO}_{2}$ mineralization. This effect is enhanced in areas where the $\mathrm{CO}_{2}$ intensity of energy production is high. The precision of the predicted $\mathrm{CO}_{2}$ reduction for homogeneously solidified slag could be improved by empirically determining the PL depth of such slag under mild mineralization conditions. Figures 4 and 5 indicate that quenched, small $T_{U}$-solidified slag provides the greatest $\mathrm{CO}_{2}$ reduction. The large GSD of small $T_{U}$ slag makes the generation of microfractures via quenching especially efficient, reducing the required grinding energy. The variation in grinding

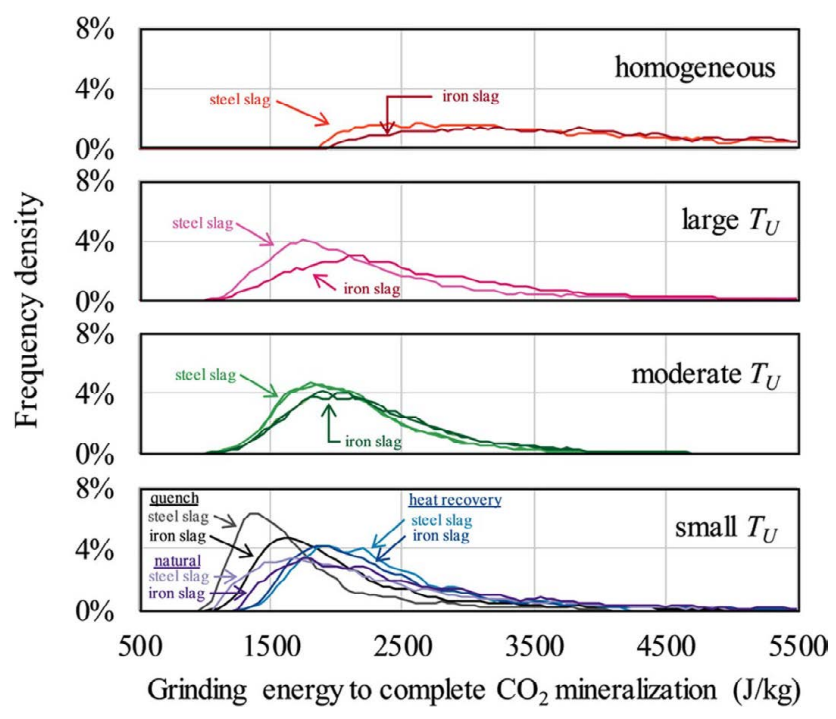

Fig. 4. Histograms of the energy intensity of grinding iron and steel slags to achieve complete conversion of $\mathrm{Ca}$ and $\mathrm{Mg}$ to carbonates according to Monte Carlo simulation (5 000 runs per condition). Bins are set at every $50 \mathrm{~J} / \mathrm{kg}$. (Online version in color.)

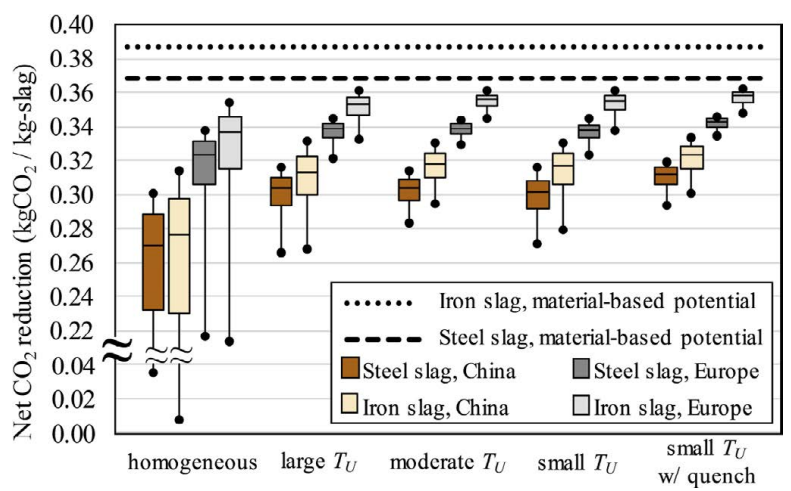

Fig. 5. Net $\mathrm{CO}_{2}$ reduction of iron and steel slag-based $\mathrm{CO}_{2}$ mineralization in China and Europe based on solidification and cooling conditions. Boxes show median, lower and upper quartile; whiskers show 5\% and 95\% values. (Online version in color.) energy and net $\mathrm{CO}_{2}$ mineralization is minimal for all other solidification and cooling methods. Large variation in net $\mathrm{CO}_{2}$ reduction is seen between ironmaking and steelmaking slag. The use of industry average slag compositions conceals the intra-industry mineralogical variation, in turn producing grinding energy and $\mathrm{CO}_{2}$ reduction ranges that may be reasonable for a single facility, but are too constrained for the ISM industry as a whole. Small $T_{U}$ solidification methods should largely counteract the compositional variations as the thermodynamically-preferred species show minimal variation at the level of compositional variation observed between ISM facilities using equivalent equipment and methods. The local $\mathrm{CO}_{2}$ intensity of energy generation remains the strongest influence on slag-based $\mathrm{CO}_{2}$ mineralization efficacy. This trend should hold for all $\mathrm{CO}_{2}$ mineralization technologies, thus highlighting the importance of countries moving to lower $\mathrm{CO}_{2}$ intensity energy sources.

\section{Conclusions}

In this work, the properties of ironmaking and steelmaking slag (i.e., mineralogy, crystallinity, GSD, micromorphology, and PSD) were shown to have a significant effect on its behavior under $\mathrm{CO}_{2}$ mineralization conditions (i.e., grinding energy, mineral locking, product layer depth). It was further demonstrated that the slag properties are sensitive to the solidification and cooling conditions applied to molten slag. These magnitude of these effects was quantified over the range of solidification and cooling conditions typical to ISM processes. It was shown that the factors effecting net $\mathrm{CO}_{2}$ reduction of slag-based $\mathrm{CO}_{2}$ mineralization follow the general trend of $\mathrm{CO}_{2}$-intensity of energy $>$ slag mineralogy $>$ solidification and cooling method. It was noted that slag mineralogy is determined by solidification and cooling method, highlighting its central importance.

A slow solidification method (small $T_{U}$ ), coupled with quenching the hot, solid slag was shown to produce the largest net $\mathrm{CO}_{2}$ reduction. It was noted that this method also circumvents the issue of compositional variation of slag. Homogeneous solidification methods (e.g., RCA) were shown to dramatically increase grinding energy, suggesting abundant caution in their use is prudent if they are to be used for $\mathrm{CO}_{2}$ mineralization or as ggbs. Studies into the PL depth of homogeneously solidified slag to provide more accurate analysis of $D_{f}$ are warranted.

All solidification and cooling conditions provided net $\mathrm{CO}_{2}$ reductions from ISM slag without the use of chemical additives or extreme temperatures and pressures. These results suggest current technology and techniques are sufficient to begin reducing the $\mathrm{CO}_{2}$ intensity of ISM through slag-based $\mathrm{CO}_{2}$ mineralization. It seems reasonable to suggest that research efforts should be switched from exploring energy-intensive thermochemical $\mathrm{CO}_{2}$ mineralization pathways to controlling the slag properties at the point of production at the ISM facility. For all methods this paper highlighted the importance of properly quantifying the properties of slag used in experiments; of primary importance are supplying the complete PSD, the GSD, and the mineralogical composition.

Several niche areas of slag-based $\mathrm{CO}_{2}$ mineralization deserve more attention based on these results of this paper. 
The quantification and control of slag porosity can potentially increase the specific surface area significantly, but feedbacks with mineralization reactions and dependence on solidification techniques makes this difficult to quantify at present. Slag abrasion concurrent to $\mathrm{CO}_{2}$ mineralization may greatly reduce the grinding energy due to the lower specific grinding energy of carbonates (Table 1), the lower energy of the interphase bonds inherent to the product layer, and the smaller surface area required per abrasive event compared to fracture events. Additionally, abrasion concurrent to $\mathrm{CO}_{2}$ mineralization would counteract the passivating effects of the product layer.

\section{Acknowledgements}

We would like to give our appreciation to the Japanese government for providing Mr. Myers with the Monbukagakusho (MEXT) Scholarship which helped to make this research possible.

\section{REFERENCES}

1) K. Horii, N. Tsutsumi, T. Kato and Y. Kitano: Nippon Steel Tech. Rep., 104 (2013), 123.

2) H. Zhang, H. Wang, X. Zhu, Y.-J. Qiu, K. Li, R. Chen and Q. Liao: Appl. Energy, 112 (2013), 956.

3) D. J. M. Flower and J. G. Sanjayan: Int. J. Life Cycle Assess., 12 (2007), 282.

4) Mineral Commodity Summary, U.S. Geological Survey, Reston, VA, (2017), 88.

5) M. Barati, S. Esfani and T. A. Utigard: Energy, 36 (2011), 5440.

6) International Energy Agenecy: $\mathrm{CO}_{2}$ Emissions from Fuel Combustion: Highlights, IEA Publishing, Paris, (2016), 3.

7) Q. Zhang, X. Zhao, H. Lu, T. Ni and Y. Li: Appl. Energy, 191 (2017), 502 .

8) J. M. Manso, J. A. Polanco, M. Losanez and J. J. Gonzalez: Cem. Concr. Compos., 28 (2006), 528.

9) J. Xie, S. Wu, L. Zhang, Y. Xiao and W. Ding: J. Clean. Prod., 133 (2016), 78.

10) N. Mac Dowell, P. S. Fennell, N. Shah and G. C. Maitland: Nat. Clim. Chang., 7 (2017), 243.

11) L. Sussams and J. Leaton: Expect the Unexpected, Grantham Institute, London, (2017), 1

12) W. J. J. Huijgen, G. J. Ruijg, R. N. J. Comans and G.-J. Witcamp: Ind. Eng. Chem. Res., 45 (2006), 9184.

13) E. Georgakopoulos, R. M. Santos, Y. W. Chiang and V. Manovic: Greenh. Gas. Sci. Technol., 6 (2016), 470.

14) D. Mombelli, C. Mapelli, S. Barella, C. Di Cecca, G. Le Saout and E. Garcia-Diaz: J. Environ. Chem. Eng., 4 (2016), 1050.

15) N. M. Piatak, M. B. Parsons and R. R. Seal II: Appl. Geochem., 57 (2015), 236.
16) D. Daval, O. Sissmann, N. Menguy, G. D. Saldi, F. Guyot, I. Martinez, J. Corvisier, B. Garcia, I. Machouk, K. G. Knauss and R. Hellmann: Chem. Geol., 284 (2011), 193.

17) D. Daval, I. Martinez, J. Corvisier and N. Findling: Chem. Geol., 265 (2009), 63.

18) F. Guyot, D. Daval, S. Dupraz, I. Martinez, B. Menez and O. Sissman: C. R. Geosci., 343 (2011), 246.

19) D. Tromans and J. A. Meech: Miner. Eng., 14 (2001), 1359.

20) M. Bodor, R. M. Santos, L. Kriskova, J. Elsen, M. Vlad and T. M. Gerven: Eur. J. Mineral., 25 (2013), 533.

21) W. Ashraf and J. Olek: J. Mater. Sci., 51 (2016), 6173

22) L. M. Anovitz and D. R. Cole: Rev. Mineral. Geochem., 80 (2015), 61.

23) R. C. Atwood and P. D. Lee: Acta Mater., 51 (2003), 5447.

24) D. Tromans and J. A. Meech: Miner. Eng., 15 (2002), 263.

$25)$ D. Alvarez and J. C. Abanades: Ind. Eng. Chem. Res., 44 (2005), 5608.

26) A. Polettini, R. Pomi and A. Stramazzo: Chem. Eng. J., 298 (2016), 26.

27) L. Little, A. N. Mainza, M. Becker and J. Wiese: Miner. Eng., 111 (2017), 148

28) D. W. Fuerstenau and A. Z. M. Abouzeid: Int. J. Miner. Process., 57 (2002), 161.

29) R. M. Santos, J. V. Bouwel, E. Vandevelde and G. Mertens: Int. J. Greenh. Gas Control, 17 (2013), 32.

30) Y. T. Yuen, P. N. Sharatt and B. Jie: Environ. Sci. Pollut. Res., 23 (2016), 22309.

31) D. Tromans and J. A. Meech: Miner. Eng., 15 (2002), 1027.

32) D. Tromans and J. A. Meech: Miner. Eng., 17 (2004), 1.

33) P. Vieillard: Geochim. Cosmochim. Acta, 58 (1994), 4065

34) A. Jain, S. P. Ong, G. Hautier, W. Chen, W. D. Richards, S. Dacek, S. Cholia, D. Gunter, D. Skinner, G. Ceder and K. A. Persson: $A P L$ Mater., 1 (2013), 011002.

35) B. Wang, Y. Yu, Y. J. Lee and M. Bauchy: Front. Mater., 2 (2015), 11.

36) H. Purwanto, T. Mizuochi, H. Tobo, M. Takagi and T. Akiyama: Mater. Trans., 45 (2014), 3286.

37) M. Pehnt and J. Henkel: Int. J. Greenh. Gas Control, 3 (2009), 49.

38) A. V. Mokshin and B. N. Galimzyanov: J. Chem. Phys., 142 (2015), 104502.

39) M. Gautier, J. Poirier, F. Bodenan, G. Franceschini and E. Veron: Int. J. Miner. Process., 123 (2013), 94.

40) D. H. St John, A. Prasad, M. A. Easton and M. Qian: Metall. Mater. Trans. A, 46A (2015), 4868.

41) J. Liu, Q. Yu, W. Duan and Q. Qin: Environ. Prog. Sustain. Energy, 34 (2015), 485.

42) M. Loncnar, A. Mladenovic, M. Zupancic and P. Bukovec: J. Min. Metall. Sect. B, 53 (2017), 19.

43) H. Tobo, Y. Miyamoto, K. Watanabe, M. Kuwayama, T. Ozawa and T. Tanaka: ISIJ Int., 54 (2014), 704.

44) C. Schmetterer and P. J. Masset: J. Phase Equilib. Diffus., 33 (2012), 261.

45) L. M. Juckes: Miner. Process. Extr. Metall., 111 (2002), 120.

46) J. Chang, Y. Fang and X. Shang: Mater. Struct., 49 (2016), 4417.

47) P. G. Debenedetti and F. H. Stillinger: Nature, 9 (2001), 259.

48) T. J. Lu and N. A. Fleck: Acta Mater., 46 (1998), 4755.

$49)$ C. A. Myers and T. Nakagaki and T. Mitamura: Energy Procedia, 114 (2017), 6246. 